\title{
Hochkonjunktur für Radiotracer
}

Noch ist der Prototyp in Bau, doch Simon Cherry sät Zuversicht: Bald soll er in Betrieb sein, der erste Ganzkörper-Positronenemissionstomograf (TB-PET). Cherry, Protagonist und renommierter Experte in Sachen Positronenemissionstomografie (PET), arbeitet mittlerweile an der Universität von Kalifornien in Davis, wo er das "Explorer-Konsortium" mit weiteren TB-PET-Forschern der USA vorantreibt. Hauptvorteil der TB-Technik soll sein, geringste Radiotracer-Konzentrationen dergestalt auszunutzen, ein vollständiges Bild aller Organe in einem Durchgang zu erhalten. Cherrys Vision: Selbst Schwangere oder Kleinkinder profitieren von Neuerungen der Nuklearbildgebung - wenn der Zeitplan klappt, schon ab 2018 [Cherry SR et al. Sci Transl Med. 2017;9(381)].

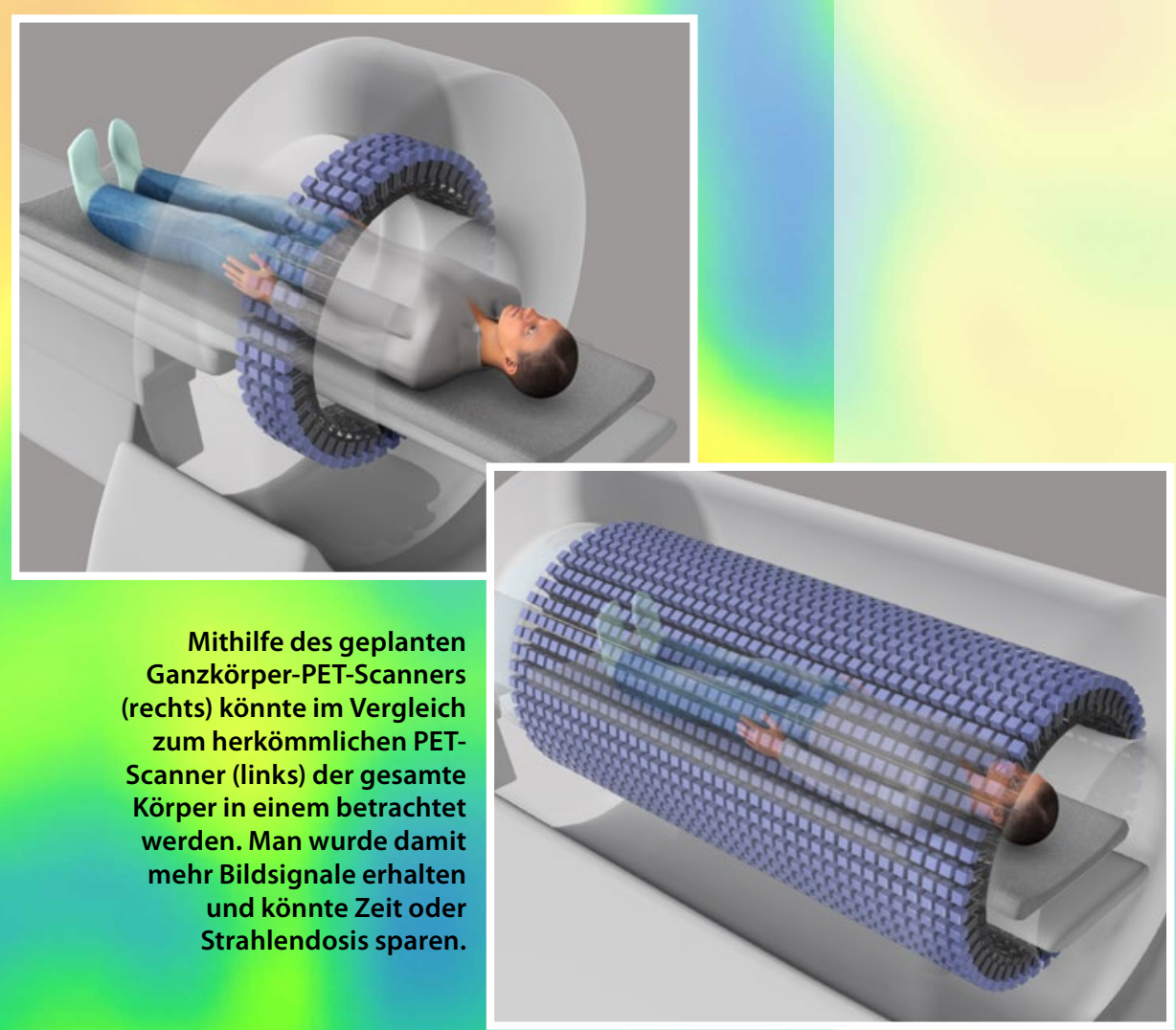

\section{Einzug auch in die MRT?}

Magnetresonanztomografie (MRT) und Radiotracer - wie geht das zusammen? Imaging-Experten der University of Virginia machen es vor. Gordon Cates und Kollegen setzen einen polarisierten Tracer ein, der sowohl MR- als auch Röntgen-Detektoren "füttert". Das Zusammenspiel beider Modalitäten soll besonders detailreiche Bilder liefern [Zheng Y et al. Nature. 2016;537(7622):652-5]. Als "fantastische Idee" bezeichnet Richard Bowtell, Mansfield Imaging Centre an der Universität von Nottingham, das neue Tracerkonzept [Bowtell R. Ibidem 621-2]. 